\title{
Site Effeets in Structural Response Predictions of Inelastic SDOF Oscillators
}

\author{
Dominic Assimaki, ${ }^{\text {a) }}$ M.EERI, Wei Li,,${ }^{\text {a) }}$ and Michalis Fragiadakis, ${ }^{\text {b) }}$ M.EERI
}

\begin{abstract}
We study how the inelastic structural response predicted via synthetic seismograms is affected by the selection of site response models in ground motion simulations. We first generate synthetics for multiple scenarios and site conditions in Southern California using attenuation relations, site specific linear, viscoelastic and nonlinear analyses, and estimate the ground motion variability that results from the soil model selection. We next use bilinear single degree-offreedom oscillators to demonstrate how this variability propagates to the inelastic structural response predictions. Results show high bias and scatter of the inelastic displacement ratio predicted using the empirical and linear elastic site response models relative to the nonlinear, for periods close to the fundamental period of the site. For the synthetic motions and sites used, we derive empirical correlations between the amount of bias and period range where it manifests, and selected input motion and site parameters. [DOI: 10.1193/1.4000056]
\end{abstract}

\section{INTRODUCTION}

With the emerging trends of performance-based earthquake engineering, nonlinear analyses are increasingly involved in the aseismic design of structures. Since the design level ground motions are scarce, engineers often rely on the use of artificial time-histories, modified from real earthquake recordings to be compatible with regional hazard-consistent design spectra (Design Spectrum Compatible Acceleration Time History, DSCTH). Indeed, the Uniform Hazard Spectrum (UHS) evaluated from Probabilistic Seismic Hazard Analyses (PSHA) of regional ground motion data is nowadays the most frequently used target spectrum in seismic structural analysis. Among others, Reiter (1990), Naeim and Lew (1995), Bommer et al. (2000) and Katsanos et al. (2010) questioned the validity of using the UHS as the target spectrum of matching procedures, arguing that by representing the spectral envelope of different seismic sources, it may yield unrealistic design ground motions.

Alternatively, synthetic ground motions computed via stochastic or physics-based fault rupture simulations may be used in nonlinear structural performance estimations. The recent advancements in the numerical representation of dynamic source rupture predictions as well as the development of three-dimensional crustal velocity and fault system models for seismically active regions have led to broadband ground motion simulations of realistic seismic waveforms over the engineering application frequency range $(<10 \mathrm{~Hz})$. To investigate the accuracy of structural response predictions obtained via synthetic ground motions, Bazzurro et al. (2004) used seven source simulation techniques to compute the structural response of

a) Georgia Institute of Technology, School of Civil and Environmental Engineering, Atlanta, GA30332

b) National Technical University of Athens, Department of Civil and Environmental Engineering, Athens, Greece 
inelastic Single Degree of Freedom (SDOF) oscillators, and statistically compared the results to the structural response predicted using real accelerograms. They showed that the synthetic ground motions produce structural responses that are less variable and less severe than those caused by real records in the short period range, which corresponds to range of wavelengths comparable to the thickness of near-surface soil layers whose inelastic response was not simulated by Bazzurro et al. (2004).

Indeed, the response of soils to strong earthquake loading has been shown to significantly affect the amplitude, frequency content and duration of seismic motions (e.g., Wiggins 1964, Idriss and Seed 1968, Borcherdt and Gibbs 1976, Joyner et al. 1976, Berrill 1977, Duke and Mal 1978, Chin and Aki 1991, Darragh and Shakal 1991, Hartzell 1992, Silva and Stark 1992, Su et al. 1992), and the consequent effects of site response on the performance of structures have been investigated in the past. More specifically, Whitman and Protonotarios (1977) studied the inelastic response of structures with different fundamental periods to sitemodified ground motions, and suggested that one should be conservative in selecting design forces for stiff structures resting upon soft ground. O'Connor and Ellingwood (1992) compared the statistics of demand parameters obtained from ground motions generated using three alternative site-dependent stochastic models, that is, Modified Kanai-Tajimi model (Tajimi 1960, Kanai 1961, Paparizos, 1986), Boore's spectral model (Boore 1983) and the Auto-Regressive Moving Average (ARMA) model (Ellis and Cakmak 1987). They concluded that no stochastic model alone was sufficient to fully characterize the ground motion and reproduce the structural inelastic response, and that each model parameter affected differently the various response quantities. Miranda (1993) evaluated the strength reduction factor $(R)$ demands of SDOF systems for ground motions recorded on firm and soft sites. He observed that strength reduction factors of systems on soft soil sites with periods of vibration near the predominant period of the ground motion are typically much larger than the displacement ductility ratio. As a result, the response of those systems was shown to deviate from the equal displacement rule. This observation was confirmed by subsequent studies by the author (Miranda 2000, Ruiz-García and Miranda 2004), where it was shown that the inelastic deformation ratios of SDOF systems from motions recorded on soft sites are much lower that those obtained using motions recorded on firm sites, provided that the fundamental period of the SDOF oscillator is close the fundamental period of the soft site.

The above studies confirm that the response of soil layers does affect the inelastic response of structures, and intuitively, if the ground motion is strong enough to cause inelastic structural deformation, it should most probably also trigger nonlinear effects particularly at soft sites. The extent, however, to which soil nonlinearity affects the inelastic structural response, has not been quantitatively established, primarily due to lack of a statistically significant number of strong ground motion records on soft sites, and the coarse classification of site conditions as either soil or rock adopted in the above studies. For example, the average PGA of ground motions collected by Ruiz-García and Miranda (2004) is on the order of $0.03 \mathrm{~g}$, which is not strong enough to cause nonlinear effects even for soft sites. As a result, limited guidance exists both in engineering practice and in the seismological literature regarding the soil models that should be employed for the prediction of site response in synthetic ground motion simulations intended for inelastic structural response analyses. 
In this study, we illustrate how the selection of site response model in synthetic ground motion simulations affects the inelastic structural performance predictions of SDOF oscillators. For this purpose, we combine geotechnical information and broadband ground motion synthetics at characteristic soft sites in Southern California, and investigate the variability in structural demand caused by the selection of soil model in regional earthquake simulations. Using synthetic motions, we are able to subject the soil profiles to design level ground motions of different magnitude and distance combinations, and successively study the demand on buildings subjected to ground motions as a function of the site response characteristics. The outcome of this study is intended to contribute to the development of quantitative guidelines for the efficient integration of nonlinear site response models into large-scale, end-to-end, physics-based ground motion simulations intended for structural performance predictions.

The soil sites used in this study were compiled by Stewart and colleagues as part of the PEER 2G02 project Calibration Sites for Validation of Nonlinear Geotechnical Models (http://cee.ea.ucla.edu/faculty/CalibrationSites/Webpage/main.htm). Detailed $100 \mathrm{~m}$ velocity profiles are available for the majority of sites, along with the dynamic soil parameters expressed as modulus reduction and material damping curves. To investigate the role of soil model selection in the evaluation of structural response, we implement four frequently employed site response methodologies, which are discussed in the ensuing. The structural performance assessment variability is evaluated in terms of the bias and uncertainty resulting from the selection of soil model on the inelastic deformation ratio of bilinear SDOF systems.

\section{SITE CONDITIONS AND BROADBAND GROUND MOTION SIMULATIONS}

Table 1 lists the sites used in this study and their corresponding NEHRP site classification based on the weighted average shear wave velocity of the top $30 \mathrm{~m}$ of the profile $\left(V_{S 30}\right)$. With the exception of the Port Island site, all other sites are located in Southern California. In terms of site conditions, we investigate the response of 8 NEHRP class C sites, 11 class D sites and 5 class E sites with $V_{S 30}$ ranging from $142 \mathrm{~m} / \mathrm{sec}$ to $692 \mathrm{~m} / \mathrm{sec}$. The shear wave velocity profiles of the sites are shown in Figure 1.

Table 1. Site conditions for selected stations used in the study

\begin{tabular}{lllcc}
\hline \hline Location & Station Name & Symbol & NEHRP Site Class & $\mathrm{V}_{\mathrm{s} 30}(\mathrm{~m} / \mathrm{sec})$ \\
\hline Corralitos & Eureka Canyon Road & CLS & $\mathrm{C}$ & 463 \\
El Centro & El Centro Array \#7 & E07 & $\mathrm{D}$ & 213 \\
El Centro & Meloland Overcrossing & MEL & E & 193 \\
Emeryville & Pacific Park Plaza & EME & E & 188 \\
Gilroy & Gilroy Array \#2 & G02 & D & 300 \\
Halls Valley & Halls Valley & HAL & D & 266 \\
Los Angeles & Rinaldi Receiving Stn. & RIN & D & 328 \\
Los Angeles & Epiphany & EPI & D & 282 \\
Los Angeles & Obregon Park & OBR & C & 457 \\
Los Angeles & Sepulveda VA & SEP & C & 370 \\
\hline \hline
\end{tabular}


Table 1. (continued)

\begin{tabular}{lllcc}
\hline \hline Location & Station Name & Symbol & NEHRP Site Class & $\mathrm{V}_{\mathrm{s} 30}(\mathrm{~m} / \mathrm{sec})$ \\
\hline Newhall & Fire Station & NEW & D & 277 \\
Oakland & Outer Harbor Wharf & OOH & D & 245 \\
Pacoima & Pacoima Kagel Canyon & PKC & C & 509 \\
Redwood City & Apeel \#2 & A02 & E & 142 \\
San Francisco & International Airport & SFO & E & 214 \\
Santa Clara & IBM Almaden, Santa Teresa Hill & STH & C & 621 \\
Santa Cruz & UCSC Lick Observatory & LOB & C & 692 \\
Simi Valley & Knolls School & KNO & C & 555 \\
Sylmar & Olive View Hospital & SYL & D & 443 \\
Sylmar & Jensen Generator Bldg. & JGB & C & 526 \\
El Centro & Meloland - Vertical Array & ELC & E & 193 \\
Eureka & Somoa Bridge - Vertical Array & EUR & D & 187 \\
Kobe & Port Island - Vertical Array & KPI & D & 201 \\
Los Angeles & La Cienega - Vertical Array & LAC & D & 258 \\
\hline \hline
\end{tabular}

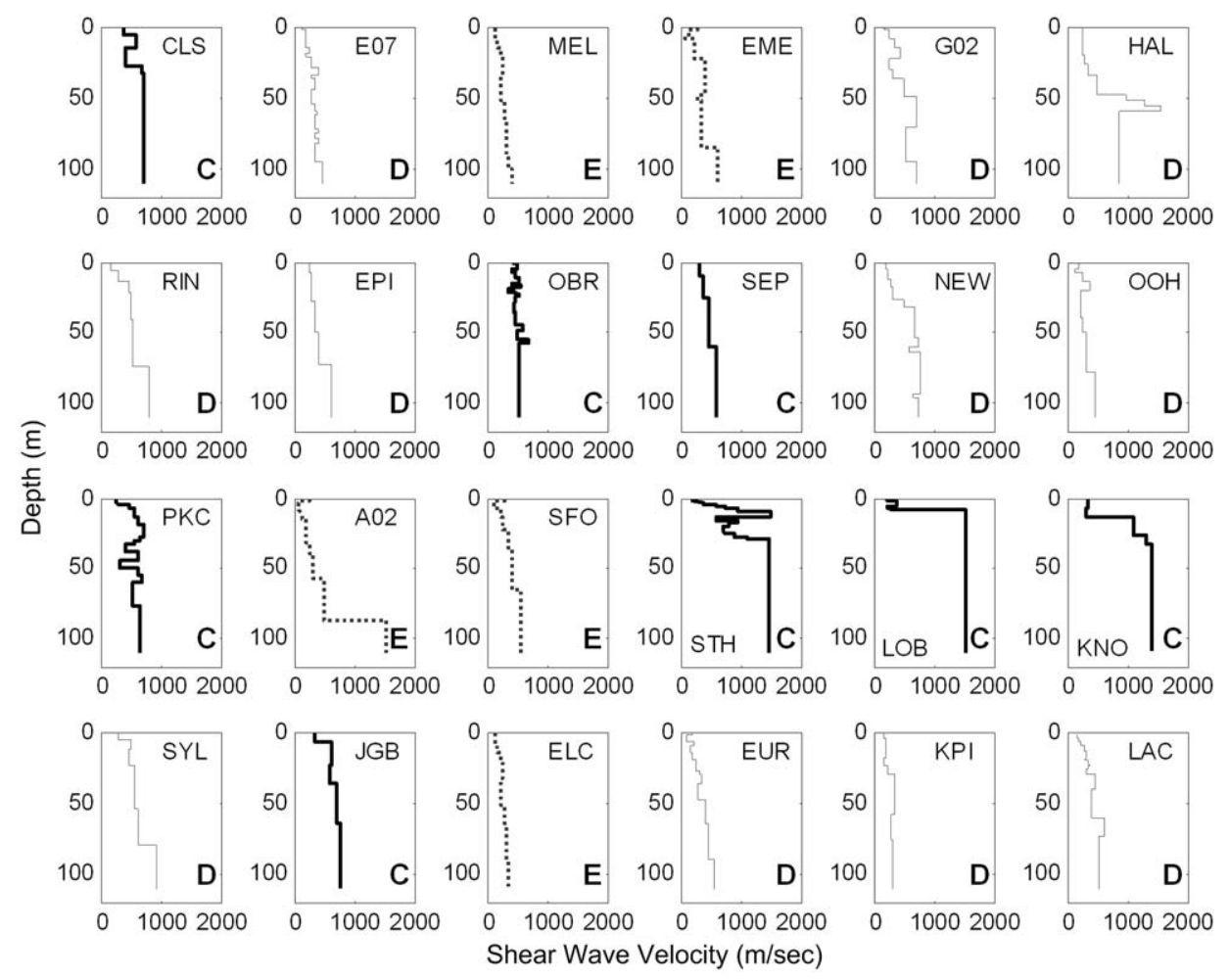

Figure 1. Shear wave velocity profiles at the ensemble of sites investigated (annotation in each figure denotes the station name and site classification of the profile in accordance to NEHRP; solid line graphs correspond to Class C profiles, light solid lines to Class D profiles, and dotted lines to Class E profiles). 
The crustal model used for the simulation of broadband ground motion synthetics was extracted from the SCEC CVM IV (http://www.data.scec.org/3Dvelocity/), and strong ground motion synthetics were computed for multiple rupture scenarios of a strike-slip fault rupture over a wide range of epicentral distances. More specifically, acceleration time-histories were evaluated using a dynamic rupture source model (Liu et al. 2006) for medium and large magnitude events $\left(M_{w}=3.5,4.0,5.0,6.0,6.5\right.$, and 7.5$)$ on a $100 \mathrm{~km}$ by $120 \mathrm{~km}$ square surface station grid (Figure 2a) with spacing of $5 \mathrm{~km}$. Note that the low frequency synthetics $(<1 \mathrm{~Hz})$ were computed for a deterministic three-dimensional crustal velocity structure using a finite-difference method, while broadband components $(1<f<$ $10 \mathrm{~Hz}$ ) were computed for a one-dimensional (1-D) heterogeneous velocity model using a frequency-wave-number method. For more details on the ground motion synthetics and the dynamic soil properties at the downhole array sites, the reader is referred to Assimaki et al (2008) and Li et al. (2009).

\section{METHODS OF SITE RESPONSE ANALYSIS}

Three widely employed site response models are used and compared in this study: the linear viscoelastic, the equivalent linear, and an incremental nonlinear model based on a modified hyperbolic constitutive law. Rather than developing a novel site response model, therefore, this study is intended to examine the implications of using models commonly employed in practice for ground motion predictions. Site response results evaluated using the three alternative models are also compared to the ground motion predictions obtained using the empirical amplification factors of the next generation attenuation relations (NGA) by Boore and Atkinson (2008).

The linear viscoelastic and equivalent linear models are based on the assumption of stationary motion, and the site response analysis using these models is formulated in the frequency domain. The equivalent linear iterative analysis is perhaps the most widely employed approach for strong motion site response predictions in engineering practice, and details on the formulation as well as assumptions of the method can be found in multiple references such as Schnabel et al (1972), Kramer (1996) and Bardet et al. (2000).

The incremental nonlinear analyses were conducted using the modified Kondner and Zelasko (MKZ) hyperbolic model (Matasovic and Vucetic 1993) to idealize the monotonic loading (backbone curve) of the soil layers:

$$
\tau=\frac{G_{\max } \gamma}{1+\beta\left(\frac{\gamma}{\gamma_{r}}\right)^{\mathrm{s}}}
$$

where $G_{\max }$ is the low-strain (linear) shear modulus, $\gamma_{r}, \beta$, and $s$ are three independent parameters that can be evaluated by fitting the modulus reduction curve, and $\tau$ and $\gamma$ denote the shear stress and the shear strain, respectively.

The extended Masing criteria (Kramer 1996) were used in the analyses to describe the unloading-reloading or hysteretic scheme, and an Iwan-type model comprising elastoplastic springs in parallel (Iwan 1967, Kausel and Assimaki 2002) was used to approximate the initial loading (backbone) curve. The central difference method (Bardet and Tobita 2001) was implemented for the solution of the 1-D off-plane shear wave propagation equation 
in layered media. Details on the numerical model discretization, boundary conditions, and implementation of the nonlinear constitutive model can be found in Assimaki et al (2008).

Results of the site-specific analyses were also compared to the ground motion predicted using the NGA empirical amplification factors by Boore and Atkinson (2008) for each of the 24 profiles investigated and the ensemble of synthetic ground motions. Attenuation relations account for site effects at soil profiles by scaling the frequency response of the BC-boundary reference site $\left(V_{S 30}=760 \mathrm{~m} / \mathrm{sec}\right)$ outcrop motion as a function of the ground motion intensity level and the site conditions; here, the Peak Ground Acceleration (PGA) was used as ground motion intensity measure, while the NEHRP $V_{S 30}$ classification (BSSC 2003) was used to describe the site conditions. Next, the amplification factors were estimated and the empirical model was employed to approximate the ground surface response as follows:

$$
F A S_{G S}(\omega)=E A F_{B A}(\omega) \cdot F A S_{R O}(\omega)
$$

where FAS denotes the Fourier amplitude spectrum, the subscripts ${ }_{G S}$ and ${ }_{R O}$ refer each to the Ground Surface and Rock Outcrop motions, and $E A F_{B A}$ is the empirical amplification factor expressed as:

$$
E A F_{B A}(\omega)=S a_{V s 30}(\omega) / S a_{B C}(\omega)
$$

where $S a_{V s 30}$ and $S a_{B C}$ are, respectively, the spectral acceleration ordinates evaluated for the soil site and the reference site. It should be noted here that an implicit assumption of this approach is that the Fourier and response spectral ratios may be used interchangeably, an empirical method that has been implemented by Graves and Pitarka (2010) among others to efficiently approximate nonlinear site effects in large-scale seismological models.

The divergence of site-specific ground motion predictions from the empirically estimated site response estimations, as well as the variability of the site-specific predictions using different soil models is next quantified as a function of the site and ground motion characteristics.

\section{NONLINEAR SOIL RESPONSE TO STRONG GROUND MOTION}

The off-plane ground surface motions of three-component synthetics computed on rock-outcrop during a previous study by the authors (Assimaki et al. 2008) were deconvolved to estimate the incident seismic motion at $100 \mathrm{~m}$ depth. This motion was next used as seismic input at the base of the soil profiles, namely at a depth where nonlinear effects are not likely to manifest during strong ground motion. Successively, the estimated incident motions were propagated through the 24 soil profiles by means of one-dimensional site response analyses using each one of the three site response models investigated. Weak ground motions (rock-outcrop $P G A<1 \mathrm{~m} / \mathrm{sec}^{2}$ ), which were considered unlikely to cause yielding of medium soft to soft profiles and the overlying structures, were excluded from the ground and structural response analyses. Overall, 510 out of 6,300 synthetic ground motions were selected for our simulations; Figure $2 b$ depicts the magnitude (M), PGA, and distance (R)-to-fault distribution of these motions.

Next, the deviation between nonlinear and linear elastic ground surface predictions for all profiles and all synthetic motions was evaluated. Assimaki et al (2008) used this measure to describe the extent of soil nonlinearity manifesting during strong ground motion. Note that 


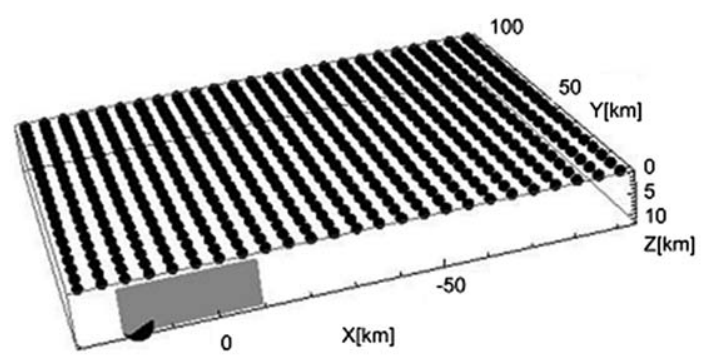

(a)


(b)

Figure 2. (a) Station layout on a $100 \mathrm{~km}^{2} \times 120 \mathrm{~km}^{2}$ grid where broadband ground-motion time histories were evaluated for a series of strike-slip rupture scenarios using the dynamic rupture model by Liu et al., 2006; (b) PGA versus magnitude and distance distribution of the synthetic rock outcrop motions used in this study.

the nonlinear model used here was benchmarked by Assimaki et al (2008) by comparison with downhole array recordings; thus, the deviation of linear site response from the 'true' nonlinear predictions is expected to increase as the intensity of nonlinear effects in the soil increases.

Denoting the spectral acceleration at period $T_{i}$ of the linear site response prediction as $S A_{i}^{L I E}$ and the spectral acceleration at period $T_{i}$ of the nonlinear prediction as $S A_{i}^{M K Z}$, the divergence between the responses is evaluated as:

$$
e_{S A}=\mu\left(e_{S A_{i}}\right)=\mu\left(\log \left(\frac{S A_{i}^{L I E}}{S A_{i}^{M K Z}}\right)\right)
$$

where the operator $\mu$ corresponds to the non-weighted average, and the subscript $i$ refers to period $T_{i}$. The averaged error is here evaluated for periods between $0.2 \mathrm{sec}$ and $2.0 \mathrm{sec}$, a range that covers the dominant period of most common structures. 
Assimaki et al (2008) expressed the error between linear and nonlinear predictions $\left(e_{S A}\right)$ as a function of the ground motion intensity, frequency content and soil profile characteristics. For soil profiles with soft layers likely to respond nonlinearly during a strong event, the amplitude and frequency content of input motion describe whether the seismic waves will "see" the soft layers and whether they "carry" sufficient energy to impose large strains and cause nonlinearity. The rock outcrop PGA $\left(P G A_{R O}\right)$ was used to describe the ground motion intensity, and a dimensionless index referred to as frequency index $(F I)$ to quantify the similarity between the transfer function of the profile and the Fourier amplitude spectrum of the incident motion. The FI is a quantitative measure of the amount of incident seismic wave energy that can be captured in the layered structure of the near surface soil profile. The larger the $F I$, the more incident seismic energy will be trapped in the near surface, and the greater amplification potential is anticipated.

If the amplified motion is characterized by a high $P G A_{R O}$, it will most likely trigger nonlinear soil effects. Assimaki et al (2009) expressed the frequency index FI as:

$$
F I=\frac{2 \sum_{i=1}^{N} A T F_{i} F A S_{i}}{\sum_{i=1}^{N} A T F_{i} A T F_{i}+\sum_{i=1}^{N} F A S_{i} F A S_{i}}
$$

where $A T F_{i}$ and $F A S_{i}$ are the amplitude of the elastic transfer function of the profile and the Fourier amplitude spectrum of incident motion at the $i^{\text {th }}$ frequency point, normalized by their corresponding peak value, and $N$ is the total number of frequency points in the range of interest, namely $0 \mathrm{~Hz}$ to twice the fundamental frequency of the site.

Figure 3 shows the variation of the $e_{S A}$ as a function of $F I$ and $P G A_{R O}$ for three sites. As can be readily seen, the deviation between linear and nonlinear predictions, $e_{S A}$, increases with increasing ground motion intensity (i.e., $P G A_{R O}$ ) and increasing frequency index $(F I)$,
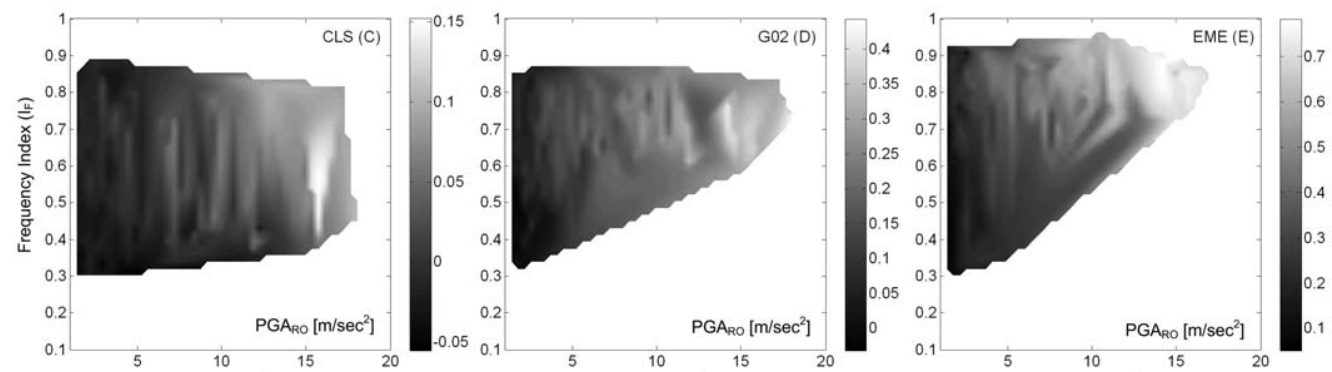

Figure 3. Contour maps of the prediction deviation of linear from nonlinear analyses $\left(e_{S A}\right)$ as a function of the peak ground acceleration $\left(P G A_{R O}\right)$ at rock-outcrop and the frequency index $(F I)$ for selected sites. 
Table 2. Regression coefficients in Equation 6 for different periods of interest

\begin{tabular}{lccc}
\hline \hline $\mathrm{T}$ & $\alpha$ & $\beta$ & $\sigma$ \\
\hline$[0.2-2.0]$ & 0.1342 & 0.0587 & 0.0442 \\
0.0 & 0.1878 & 0.0517 & 0.0689 \\
0.2 & 0.1517 & 0.0591 & 0.0712 \\
0.5 & 0.1505 & 0.0752 & 0.0777 \\
1.0 & 0.0817 & 0.0406 & 0.0534 \\
\hline \hline
\end{tabular}

and attains maximum values at the upper-right corner of the contour plot. The $P G A_{R O}-F I$ regions of large $e_{S A}$ values correspond to combinations of sites and incident ground motions with large sensitivity of the site response predictions on the selection of the soil model. In these cases, Assimaki et al (2008) recommended that nonlinear analyses should be employed to ensure credibility of the site response analyses.

Figure 3 also shows that the quantitative dependency of $e_{S A}$ on $P G A_{R O}$ and FI is sitespecific. Li et al. (2009) identified the following empirical relation between $e_{S A}$, ground motion and soil profile parameters to describe the variability in absolute $e_{S A}$ values as a function of the site characteristics:

$$
e_{S A}=\alpha \cdot \frac{760}{V_{S 30}} \cdot \frac{P G A_{R O}}{20}+\beta \cdot A m p \cdot F I+\epsilon
$$

where $\alpha$ and $\beta$ are regression coefficients, $V_{S 30}$ is the averaged shear wave velocity in the upper 30 meter soil layers in [m/sec], $P G A_{R O}$ is the Peak Ground Acceleration at rock outcrop in $\left[\mathrm{m} / \mathrm{sec}^{2}\right], A m p$ is the site amplification at the fundamental period of the soil site, $F I$ is the frequency index as defined previously, and $\epsilon$ is the normally distributed residual of the regression. Equation 6 can be used as a proxy to describe the extent of nonlinear soil effects expected at a given site when subjected to a given ground motion, and the associated uncertainties as a function of the soil profile and the ground motion characteristics. Regression coefficients $\alpha$ and $\beta$ were estimated for the ensemble of sites under investigation, which along with an error threshold $e_{S A} \leq e_{S A}^{\max }$, may be implemented to quantify whether nonlinear simulations are required for site response predictions at a given site during a given event. The values of $\alpha, \beta$ and the standard deviation of residual (denoted as $\sigma$ ) for representative periods of interest are summarized in Table 2. The empirical relation revealed by Equation 6 can also be visualized by Figure 4 .

While details of the study above are beyond the scope of the present work, the concept of soil and ground motion dependency will be used in the following sections to illustrate how the soil model implemented for the prediction of site response affects the estimation of inelastic structural performance measures.

\section{UNCERTAINTY AND BIAS IN STRUCTURAL RESPONSE PREDICTIONS}

We next investigate how the modeling variability in site response analyses propagates to the prediction of inelastic structural response for a series of nonlinear SDOF oscillators. More specifically, we estimate the bias and uncertainty in structural response introduced by the soil 


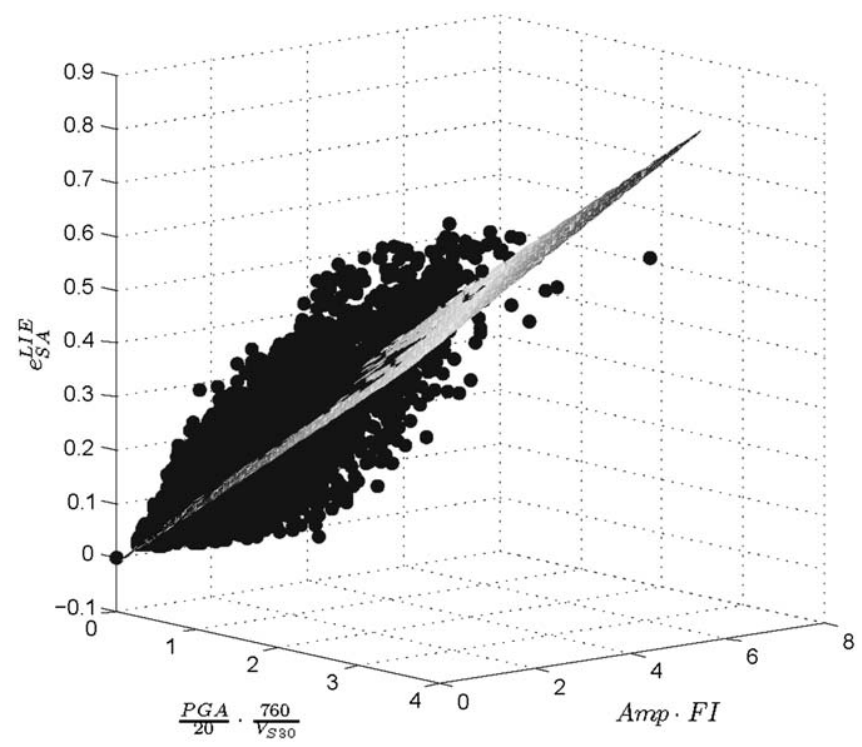

Figure 4. Prediction deviation of linear from nonlinear analyses $\left(e_{S A}\right)$ for the ensemble of site and ground motion simulations of this study.

model, using the nonlinear site response analyses as reference. The inelastic deformation ratio $(C)$ is used as an Engineering Demand Parameter (EDP) to measure the displacement demand, while its variability resulting from the selection of the soil model is mapped as a function of the site- and ground-motion characteristics described above, namely as a function of $P G A_{R O}$ and $F I$.

\section{INELASTIC DEFORMATION RATIO}

The inelastic deformation ratio $(C)$ is defined as the ratio of the peak deformation $\left(u_{\mathrm{m}}\right)$ of an inelastic oscillator to its corresponding linear $\left(u_{0}\right)$ response (see Figure 5). This ratio varies considerably as a function of period and approaches unity only in the displacement-sensitive spectral region of the oscillator response, which is the basis of the so-called equal deformation rule $\left(u_{\mathrm{m}} / u_{0}=1\right.$; Veletsos at al. 1965).

When expressed as a function of the elastic vibration period $T_{n}$ and the ductility factor $\mu$, the inelastic deformation ratio $(C)$ may be used to determine the inelastic deformation demand of a structure with given global ductility capacity; on the other hand, when expressed as a function of the elastic vibration period and the yield-strength reduction factor $R_{y}$ (Equation 7), it can be used to estimate the inelastic deformation of an existing structure with known lateral strength. Compared to the alternative indirect method of $R_{y}-\mu-T_{n}$ relations, this direct method can yield an approximately unbiased estimation of the peak deformation of an inelastic SDOF system (Miranda 2001, Chopra 2004).

A bilinear force-displacement response $f_{s}(u, \operatorname{sgn} \dot{u})$ schematically shown in Figure 5 was selected to simulate the idealized inelastic structural response of a series of SDOF oscillators. 


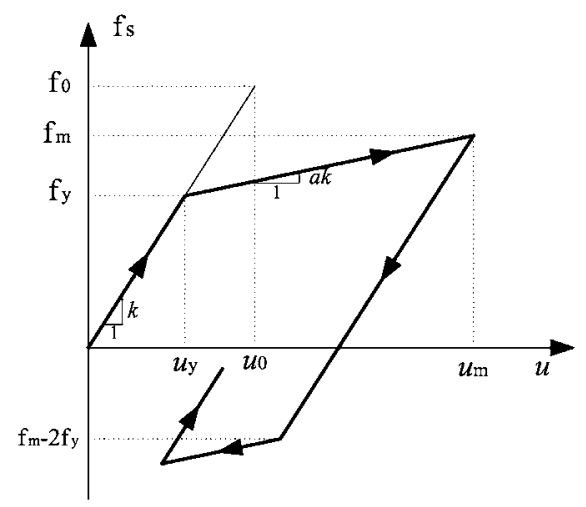

Figure 5. Bilinear force-deformation schematic of the inelastic SDOF oscillators, depicting their elastic and post-yield characteristics (after Chopra 2004).

As shown in Figure 5, the elastic stiffness of the model is $k$ and the post-yield stiffness is $\alpha k$, where $\alpha$ is defined as the post-yield stiffness ratio. The yield strength of the oscillator is $f_{y}$ and the yield deformation $u_{y}$. Within the linear elastic range namely $u=\left[0 \sim u_{y}\right]$ the system has a natural vibration period $T_{n}$ and damping ratio $\xi$. The yield strength reduction factor of the structure $\left(R_{y}\right)$ is defined as:

$$
R_{y}=\frac{f_{0}}{f_{\mathrm{y}}}=\frac{u_{0}}{u_{y}}
$$

where $f_{0}$ and $u_{0}$ are the minimum yield strength and yield deformation required for the structure to remain elastic during the ground motion, or the peak response values for the corresponding linear system. The peak force in the inelastic system is $f_{m}$ (Figure 5). The peak deformation of the bilinear system is denoted by $u_{m}$ and the corresponding ductility ratio $\mu$ is defined as:

$$
\mu=\frac{u_{m}}{u_{y}}
$$

Finally, it can be shown that the inelastic deformation ratio $(C)$ can be evaluated as:

$$
C=\frac{u_{m}}{u_{0}}=\frac{\mu}{R_{y}}
$$

When the equal displacement rule applies, $C=1$ or $\mu=R_{y}$. To ensure a uniform intermediate inelastic level in the nonlinear oscillators, we implemented the constant yield strength reduction factor $\left(R_{y}=4\right)$ approach, and also investigated the constant ductility ratio $(\mu=4)$ approach instead of fixing the oscillator's yield strength $\left(f_{y}\right)$. To ensure equal $R_{y}$ factor for the ensemble of analyses, $f_{y}$ was tuned according to the record's first mode spectral acceleration. Given the highly variable ground motion intensity in this study $(P G A=0.1 \mathrm{~g} \sim 2.0 \mathrm{~g})$ that would result in high inelastic demands on constant yield 
strength oscillators, the equal $R_{y}$ factor prevents the inelastic structural response from overshadowing the signature of site effects in the performance estimations.

\section{BIAS AND UNCERTAINTY IN PREDICTION OF INELASTIC DEFORMATION RATIO}

We next evaluate the variability in inelastic deformation ratio $(C)$ predictions for each of the site response methods for structures with different fundamental period and yield strength, $f_{y}$. Results are differentiated using subscripts corresponding to abbreviations of site response models. Specifically, the $C$ values corresponding to the empirical amplification model are denoted as $C_{E A F}$; similarly, the $C$ values corresponding to the linear visco-elastic models are denoted as $C_{L I E}$; the $C$ values of the equivalent linear models are denoted as $C_{E Q L}$; and the $C$ values of the modified Kondner and Zelasko (MKZ) nonlinear model as $C_{M K Z}$.

In this section, representative results from three sites with NEHRP class C (site CLS), D (site G02), and E (site EME) are shown to illustrate key observations of this study. The statistical correlation analysis between bias in the prediction of the displacement demand, $C$ and the site parameters using the results from all the sites is shown in the ensuing.

Figure 6 shows the mean and standard deviation of $C_{E A F}, C_{L I E}, C_{E Q L}$, and $C_{M K Z}$ for $R_{y}=4$ as functions of the fundamental period $\left(T_{n}\right)$ of the inelastic SDOF for the selected sites. The $C$ values are averaged within five different $P G A_{R O}$ bins shown in the legend to illustrate the PGA dependency. It can be readily seen that the $C_{L I E}$ curves show literally no PGA dependency, that is, the $C_{L I E}$ curves from different $P G A_{R O}$ groups are almost nondifferentiable. This is due to the fact that the site amplification of LIE is independent of the incident motion intensity, and thus uniformly alters the frequency content of the incident motion. Although the ground response intensities are highly variable, the alterations in frequency contents are the same, which results in intensity-independent $C_{L I E}$ values for the constant $R_{y}$ oscillator.

The $C_{E A F}$ curves show a slight PGA dependency and are qualitatively similar to the $C_{L I E}$ curves. The site amplification of the EAF model is derived based on the mean spectral acceleration (SA) ordinates predicted by the NGA relations. While the mean SA ordinates predicted using EAF are smoother than site-specific SA values as a result of averaging, the EAF model is was anticipated to yield similar results to the LIE model.

By contrast to the $C_{L I E}$ and $C_{E A F}, C_{E Q L}$ and $C_{M K Z}$ show obvious PGA dependency, that is, the $C_{E Q L}$ and $C_{M K Z}$ curves from different $P G A_{R O}$ groups deviate from one another, with the $C_{E Q L}$ or $C_{M K Z}$ predictions associated with higher $P G A_{R O}$ showing higher $C$ values. Since the same constant yield strength reduction factor $\left(R_{y}=4\right)$ SDOF models was used to calculate the $C_{E Q L}$ and $C_{M K Z}$ values, the only source of the $P G A_{R O}$ dependency is the difference in the frequency content of the ground motions due to the adoption of different site response models.

In both cases, the amplitude and frequency content of input motion is substantially modified as a result of the nonlinear site response for high intensity input motion, and this amplitude and frequency content modification is quite realistically captured by the 

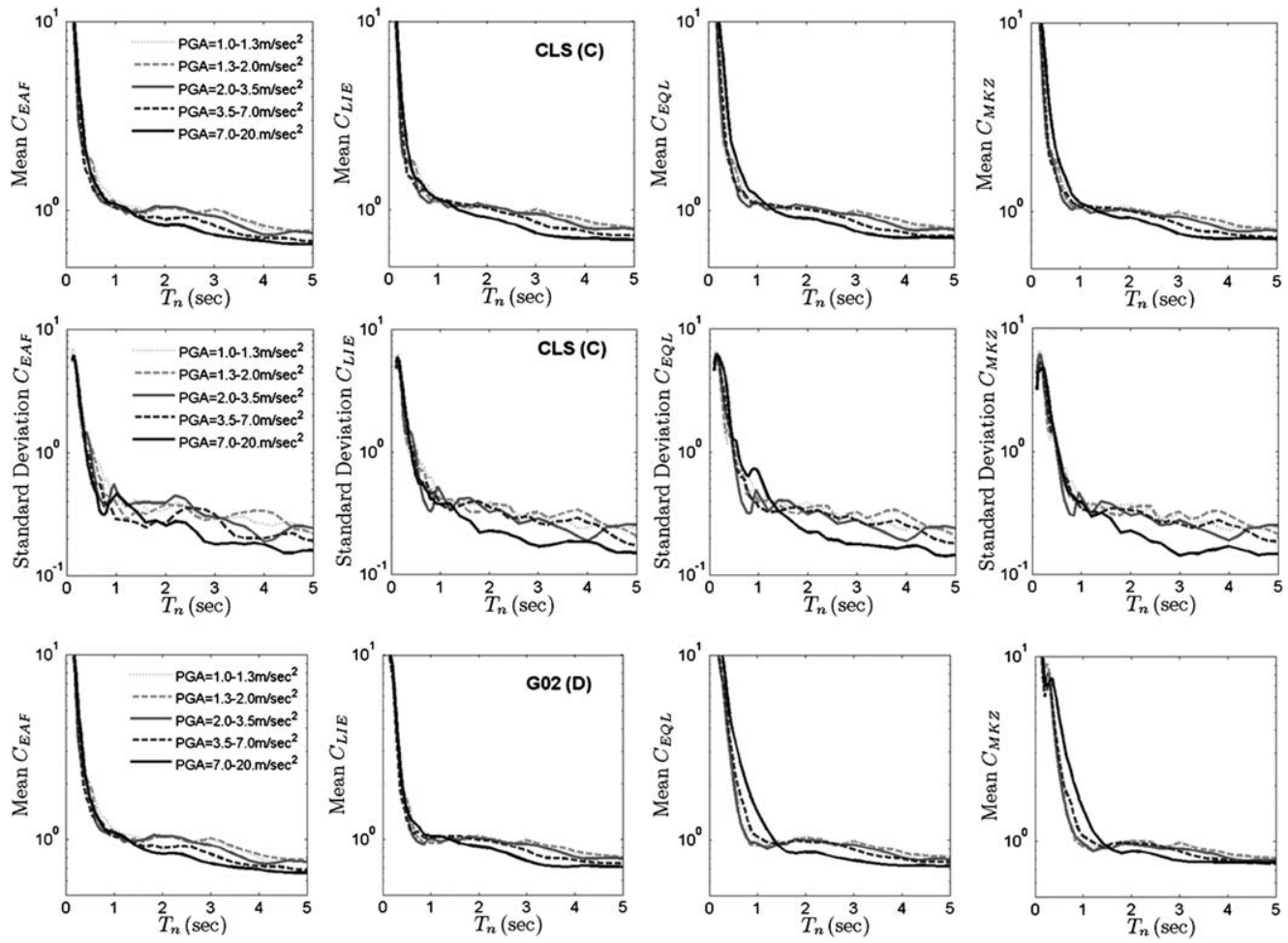

Figure 6. Mean and standard deviation of the inelastic deformation ratio $(C)$ of bilinear SDOF oscillators with constant strength reduction factors $\left(R_{y}=4\right)$ averaged within the PGA bins shown in the legend. Results are evaluated using ground surface predictions from each of the four site response models investigated, and plotted as a function of the natural elastic vibration period of the bilinear SDOF. From the left to the right column: EAF corresponds to the NGA (empirical) amplification factor model; LIE to the linear visco-elastic model; EQL to the equivalent linear model; and MKZ to the incremental modified Kondner-Zelasko model.

EQL and MKZ models. For the most part, results show that the stronger the incident motion, the larger the change in frequency content of the ground response relative to the linear elastic response, which results in the observed variability of the inelastic deformation ratio predictions, $C$. The standard deviation of $C$ values shows the same trend as the mean value of $\mathrm{C}$.

In order to quantitatively describe the effects of nonlinear site response modeling on the $C$ prediction, the bias and uncertainty are next evaluated as the ratio of the mean $C\left(Q_{\mu_{C}}\right)$ and the ratio of the coefficients of variation $(\mathrm{COV})$ of $C\left(Q_{\sigma_{C}}\right)$ respectively. Considering that the MKZ model provides the most realistic predictions based on validation studies performed by the authors in the past, the corresponding quantities (i.e., mean and COV) associated with this model are used as denominator of the ratio for each one of the three remaining models. For instance, the ratio between the mean $C$ predictions of the LIE and MKZ models is 

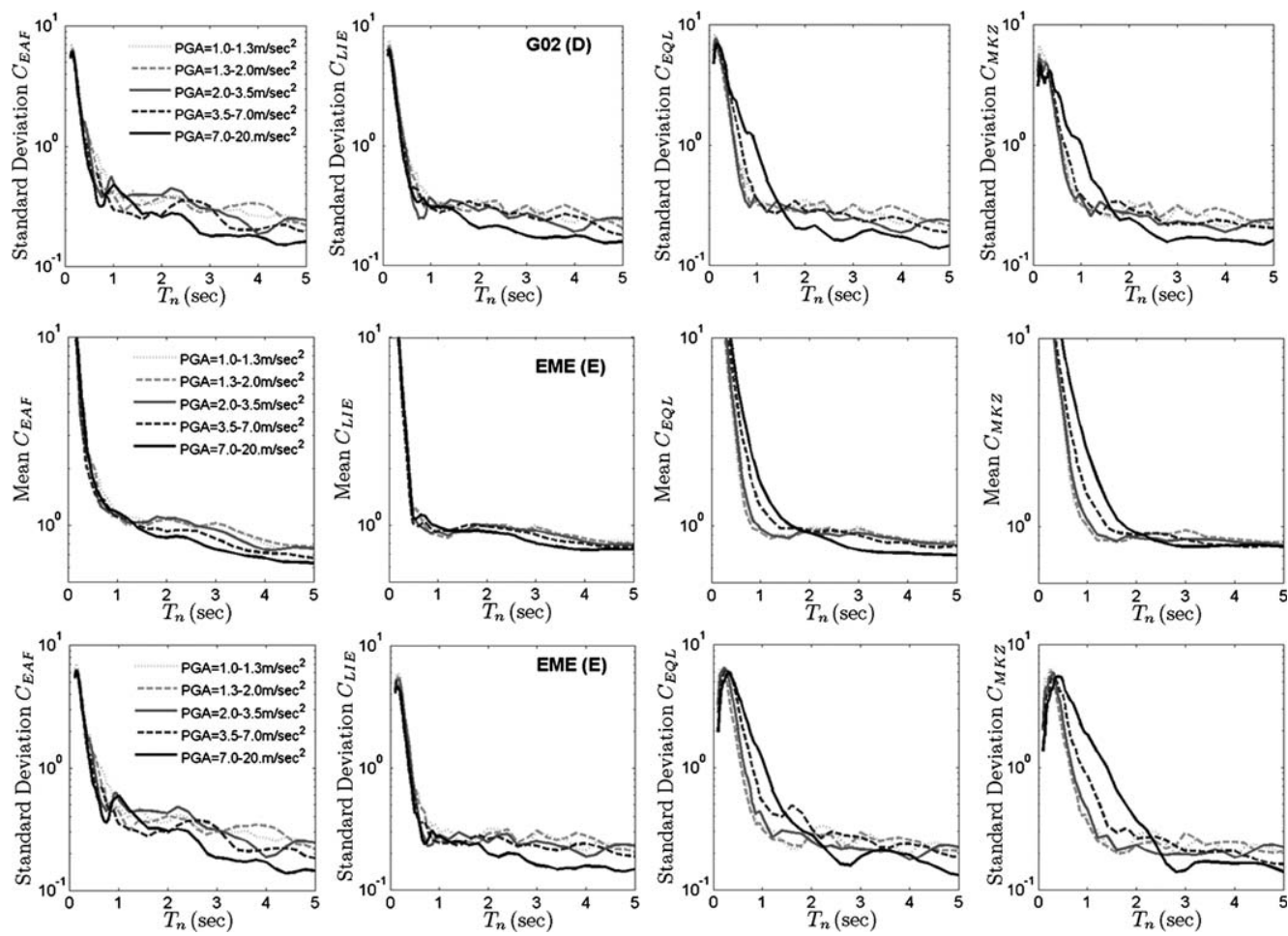

Figure 6. (continued)

expressed as $Q_{\mu_{C}}=\mu_{C_{L I E}} / \mu_{C_{M K Z}}$, and the ratio between the COV as $Q_{\sigma_{C}}=\sigma_{C_{L I E}} / \sigma_{C_{M K Z}}$. As can be seen, the deviation of $Q_{\mu_{C}}$ or $Q_{\sigma_{C}}$ from unity indicates the implications of using a particular soil model on the predictions of $C$, and therefore the propagation of ground response prediction variability to the structural inelastic performance estimation that arises from the simulation of nonlinear soil effects.

Figure 7 shows the $Q_{\mu_{C}}$ and $Q_{\sigma_{C}}$ for $R_{y}=4$ at selected sites as a function of the elastic vibration period of the SDOF system, normalized by the fundamental period of the site. The mean $\mathrm{C}$ values here are averaged within the ranges of $P G A_{R O}$ indicated by the legend. As mentioned before, a constant $R_{y}$ was here selected to depict the propagation of site response modeling variability to the inelastic structural response prediction while keeping the inelastic structural characteristics invariable.

As can be seen from Figure 7, the LIE and EAF models give biased $C$ predictions relative to the MKZ model for all three sites, and the bias reaches peak value around the abscissa of unity (the lower the value of $Q_{\mu_{C}}$, the higher the model bias relative to the nonlinear analysis), that is, when the elastic vibration period of the SDOF system is close the to natural period of the site. Furthermore, the bandwidth of bias is proportional to the natural period of the site, that is, is a function of the site stiffness. As expected, the performance of EAF model is very 

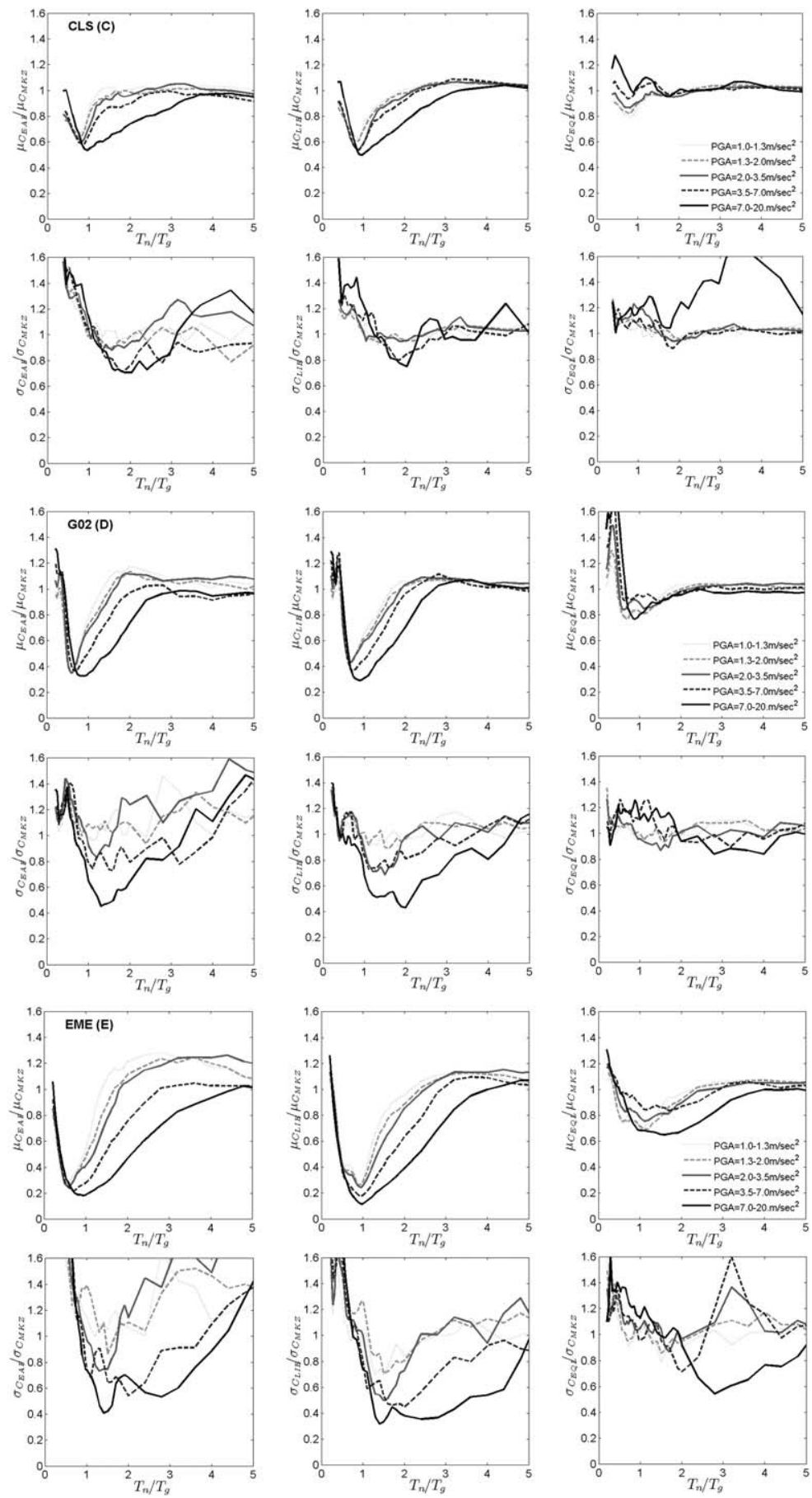

Figure 7. Mean and standard deviation of the inelastic deformation ratios relative to the predictions evaluated using the nonlinear site response model $(Q)$ for bilinear SDOF structures with $R_{y}=4$. Results are grouped within $P G A_{R O}$ bins denoted in the legend, and plotted as a function of the natural elastic vibration period of the bilinear SDOF normalized by the fundamental period of the site. 
similar to the LIE model since both of them give the same bias value and bias range. The bias in $C$ prediction caused by EQL model is much lower than that of EAF and LIE model and as expected, the stiffer the site, the better the performance of the EQL model. This is because the strain level at a stiffer site is smaller for seismic excitations of the same intensity, and the smaller the strain level, the smaller the deviation between the EQL and MKZ model predictions.

The $P G A_{R O}$ and site dependency of the bias can be clearly seen in Figure 7. As can be inferred from above, the higher the $P G A_{R O}$, the higher bias in the $C$ prediction by the LIE and EAF models. Similarly, the softer the site, the higher the bias introduced in the $C$ predictions by the LIE and EAF models. Since the $P G A_{R O}$ values and the relative stiffness of the sites are directly associated with the degree of nonlinearity in ground response, the high $P G A_{R O}$ and site dependency of $Q_{\mu_{C}}$ are attributed to the inability of LIE and EAF models to capture the nonlinear effect in the ground response. For simplicity, we take only $Q_{\mu_{C}}=\mu_{C_{L I E}} / \mu_{C_{M K Z}}$ as the San Francisco, CA (SFO) quantitative measure of the bias in the prediction of the mean $\mathrm{C}$ demand. The $Q_{\sigma_{C}}$ plot shows that the models other than MKZ model also underestimate the uncertainties, that is, standard deviation of $C$ predictions.

For each site, the $Q_{\mu_{C}}$ value in each PGA bin at the period of highest bias is plotted as function of $P G A_{R O}$ in Figure 8. Clearly, different sites show different degree of PGA
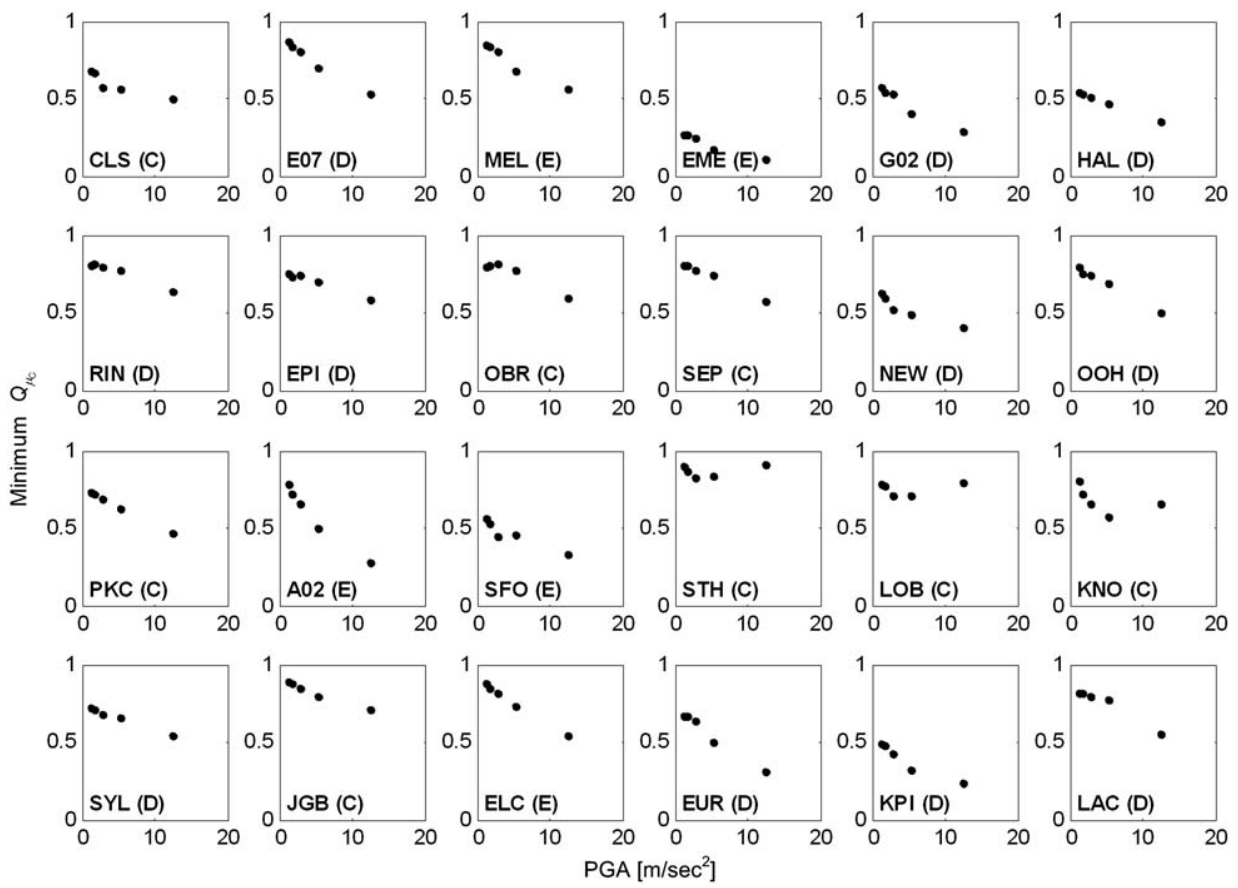

Figure 8. Minimum $Q$ value (evaluated at the period of highest bias) versus $P G A_{R O}$ for the ensemble of sites and ground motions $\left(R_{y}=4\right)$. 
dependency. If the degree of dependency is measured using the linear regression slopes to the data of each $Q_{\mu_{C}}$ versus PGA plot, and the absolute values of the slopes are denoted proportion coefficients, it can be shown that they are correlated to the $V_{S 30}$ values of the sites. Their correlation is illustrated in Figure 9, where it can be readily seen that the softer the site (i.e., lower $V_{S 30}$ value), the higher the PGA dependency of $Q_{\mu_{C}}$ value. This observation also implies that the nonlinear site effects are most likely the origin of bias in the mean $C$ estimation because softer sites are more susceptible to nonlinear deformations.

It should be noted here that although the trend in site dependency and PGA dependency of $Q_{\mu_{C}}$ is very clear when the $C$ values are grouped (averaged) in PGA bins, the original $Q_{C}$ values without averaging of $\mathrm{C}$ are highly scattered. The source of scattering is most likely the sensitivity of $Q_{C}$ to the non-stationary nature of ground motion time histories, and averaging of $Q_{C}$ within PGA bins needed to be employed to highlight the trend of interest, that is, the dependency of $Q_{\mu_{C}}$ on PGA. Figure 10 shows the minimum $Q_{C}$ value for all the motions at selected sites. As can been observed in Figure 10, the $Q_{C}$ may reach very low value even at very low PGA.

Similarly to Figure 7, $C$ values from different models may be averaged within frequency index (FI) bins before taking the ratio, to show the FI dependency of inelastic response bias. Figure 11 shows the $Q_{\mu_{C}}$ and $Q_{\sigma_{C}}$ for $R_{y}=4$ at selected sites as a function of the elastic vibration period of the SDOF normalized by the fundamental period of the site; the mean $C$ values here are averaged within the ranges of FI indicated by the legend.

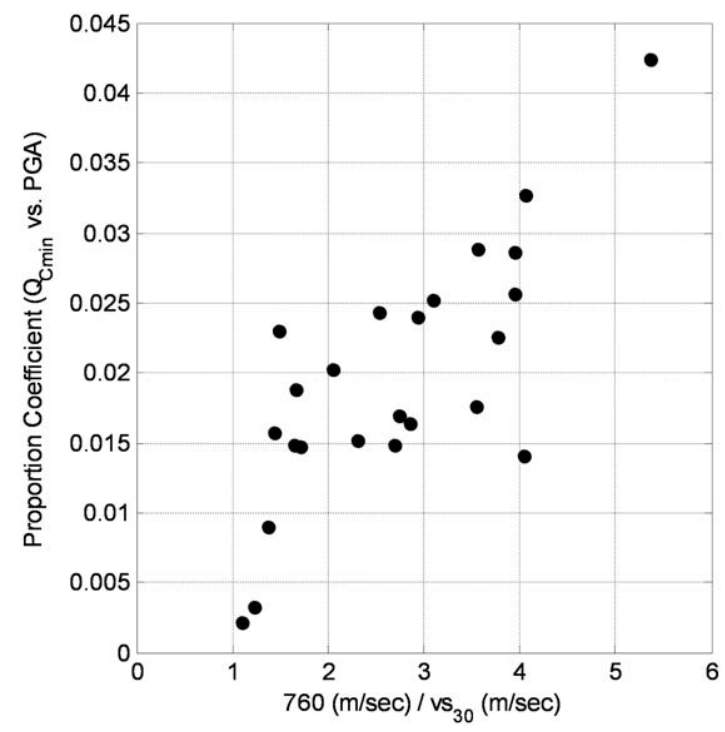

Figure 9. Proportionality coefficient (least-square fit slope of data per site in Figure 8) versus $V_{S 30}\left(R_{y}=4\right)$. 

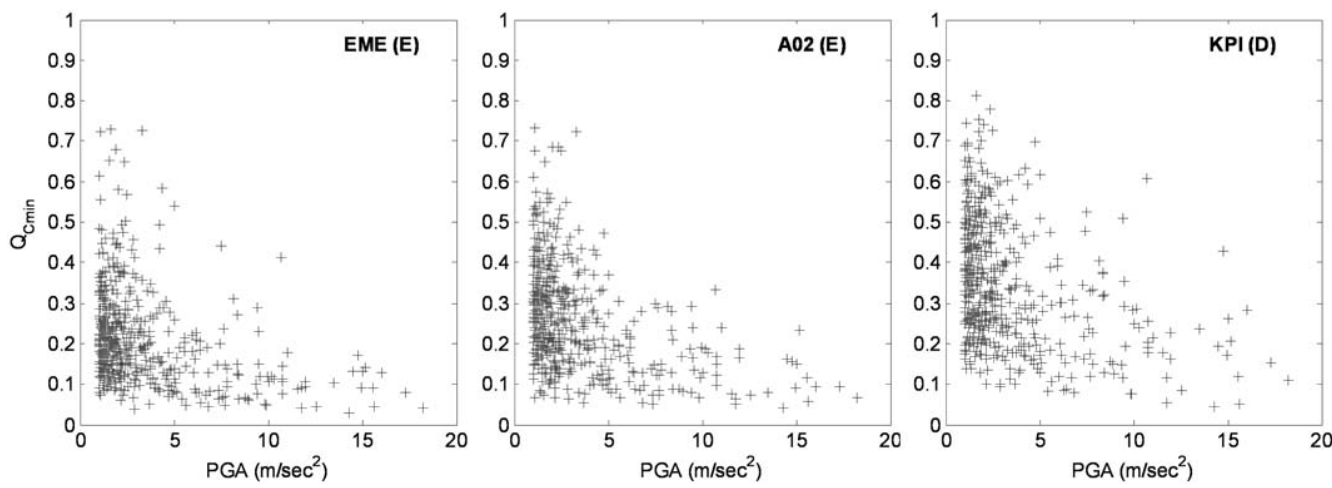

Figure 10. Minimum $Q$ value (evaluated at the period of highest bias) versus $P G A_{R O}$ at selected sites $\left(R_{y}=4\right)$. Ground motions are not averaged within $P G A_{R O}$ bins, which yields highly scattered results by contrast to Figure 8 .

The trend of bias indicated by $Q_{\mu_{C}}$ and $Q_{\sigma_{C}}$ is very similar to what shown in Figure 7, except that the FI dependency of $Q_{\mu_{C}}$ and $Q_{\sigma_{C}}$ is not as prominent as the PGA dependency. This observation is consistent with the fact that the PGA dependency estimated for the site response prediction error by the alternative models in Section 3 is stronger than the FI dependency.

Similar to Figure 8, the $Q_{\mu_{C}}$ value in each FI bin at the period of highest bias can be plotted as function of FI for all the sites as shown in Figure 12. It can be readily seen that some sites do show strong dependency of $Q_{\mu_{C}}$ on FI, while others do not. If the minimum $Q$ value of each site in Figure 12 is taken as a representative bias degree of the site, denoted as $Q_{C \min }$, one can next plot $Q_{C \min }$ versus the site amplification value (the magnitude of the transfer function) at the fundamental frequency of the site, which shown in Figure 13. Again, Figure 14 indicates that the individual minimum $Q$ values without $C$ averaging are actually very scattered and that very low $Q$ may appear even in the low PGA range.

Given that constant $R_{y}$ models were used to calculate the inelastic structural response in the analyses described above, the bias in the $C$ prediction observed is attributed to the differences in the frequency content of the ground motions evaluated using the various site response models. Such differences in the frequency content maybe significant and cause large discrepancy the $C$ prediction, independent of the associated PGA amplitude variability.

Analogous to Figure 9 and Figure 13, the bias in $C$ prediction for the constant ductility ratio case $(\mu=4)$ is plotted in Figure 15 and Figure 16 where results are grouped in terms of $P G A_{R O}$ and $I_{F}$ respectively. The general trends are almost the same as the results shown in Figures 9 and 13, while the bias in the constant ductility case is consistently less than in the case of constant strength reduction due to the stiffer structural response of the former bilinear SDOF structures. 

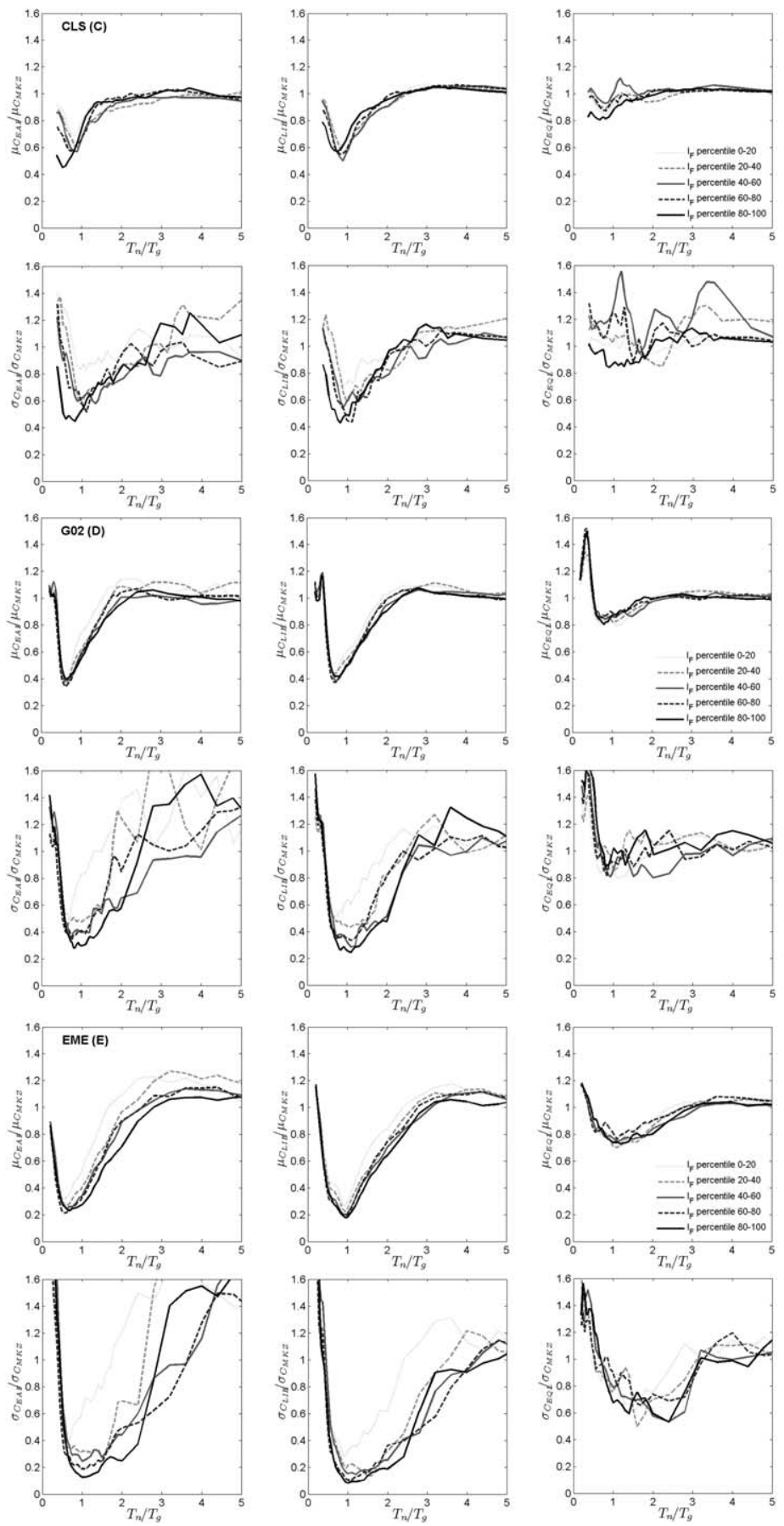

Figure 11. Mean and standard deviation of the inelastic deformation ratios relative to the predictions evaluated using the nonlinear site response model $(Q)$ for bilinear SDOF structures with $R_{y}=4$. Results are grouped within frequency index $F I$ bins denoted in the legend, and plotted as a function of the natural elastic vibration period of the bilinear SDOF normalized by the fundamental period of the site. 

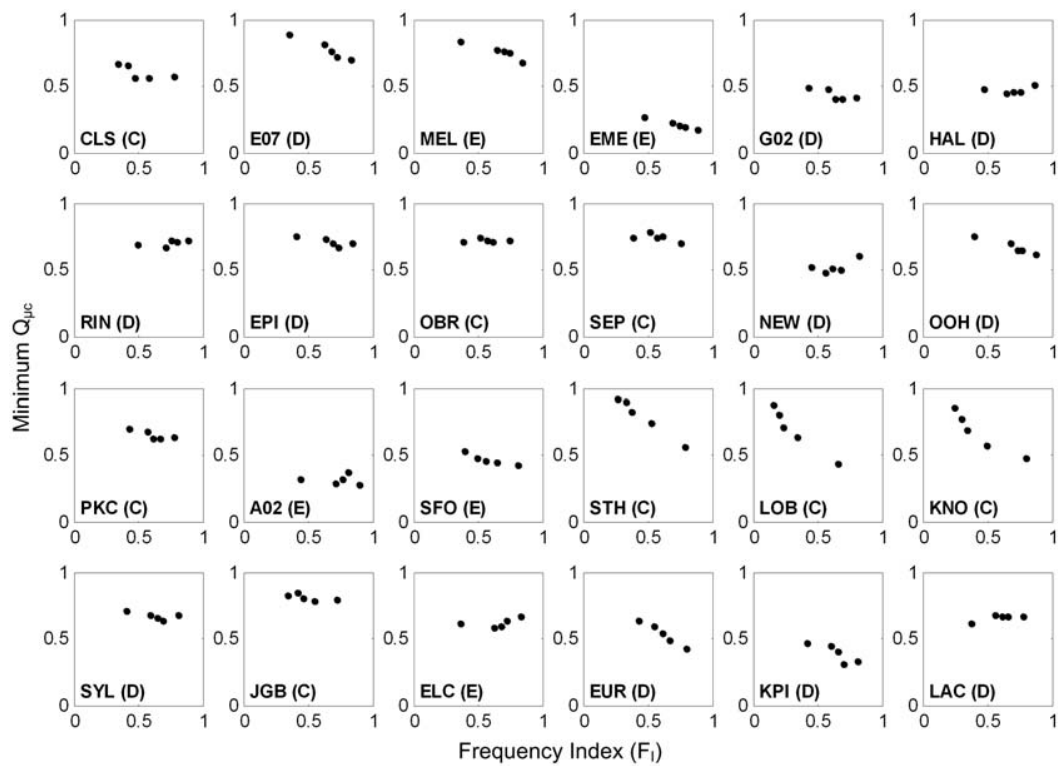

Figure 12. Minimum $Q$ value (evaluated at the period of highest bias) versus $F I$ for the ensemble of sites and ground motions $\left(R_{y}=4\right)$.

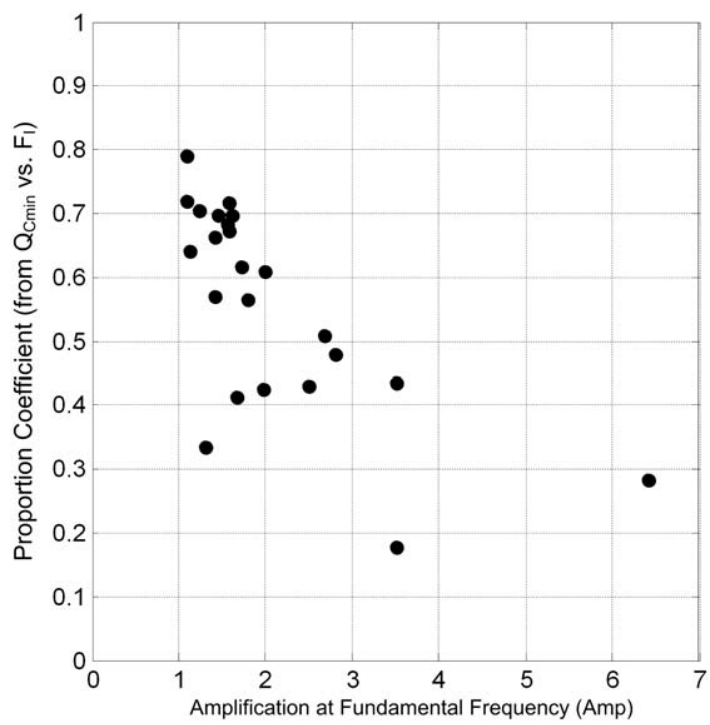

Figure 13. Proportionality coefficient (least-square fit slope of data per site in Figure 12) versus the amplification at the fundamental frequency of the site, $\operatorname{Amp}\left(R_{y}=4\right)$. 

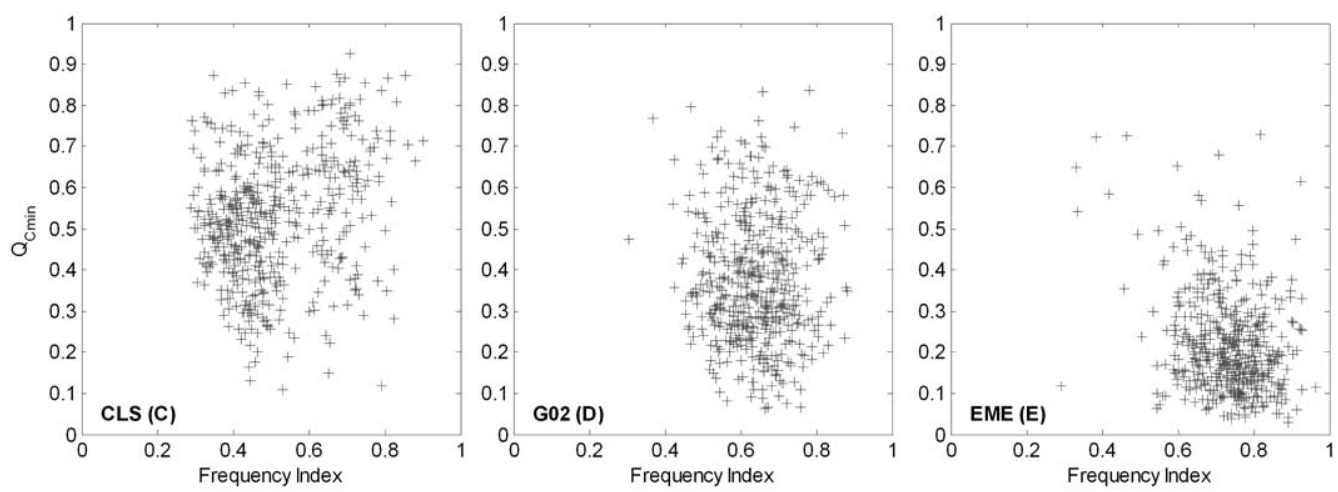

Figure 14. Minimum $Q$ value (evaluated at the period of highest bias) versus $F_{I}$ at selected sites $\left(R_{y}=4\right)$. Ground motions are not averaged within $F I$ bins, which yields highly scattered results by contrast to Figure 12 .

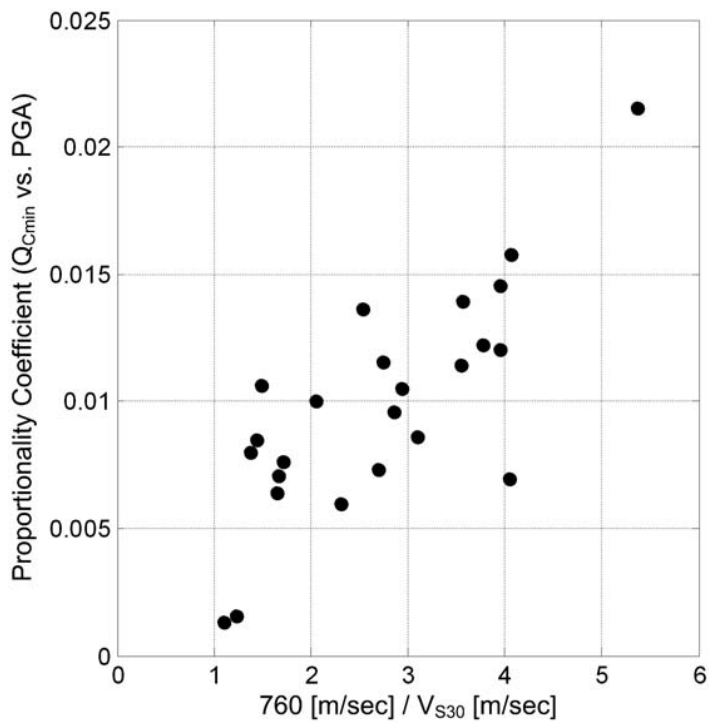

Figure 15. Proportionality coefficient of $Q_{C \min }$ versus $P G A_{R O}$ plotted against $V_{S 30}$ for constant ductility ratio inelastic SDOF oscillators $(\mu=4)$ (compare to Figure 9 for $R_{y}=4$ ).

Finally, it should be noted that the bias trends in Figures 7 and 11 are consistent with results published by Bazzurro et al. (2004), which were based on the comparison between the inelastic structural response estimated using synthetic and recorded ground motions. This consistency also implies that bias in the latter study may be caused by insufficient consideration of the nonlinear site effects in the synthetic ground motion predictions. 


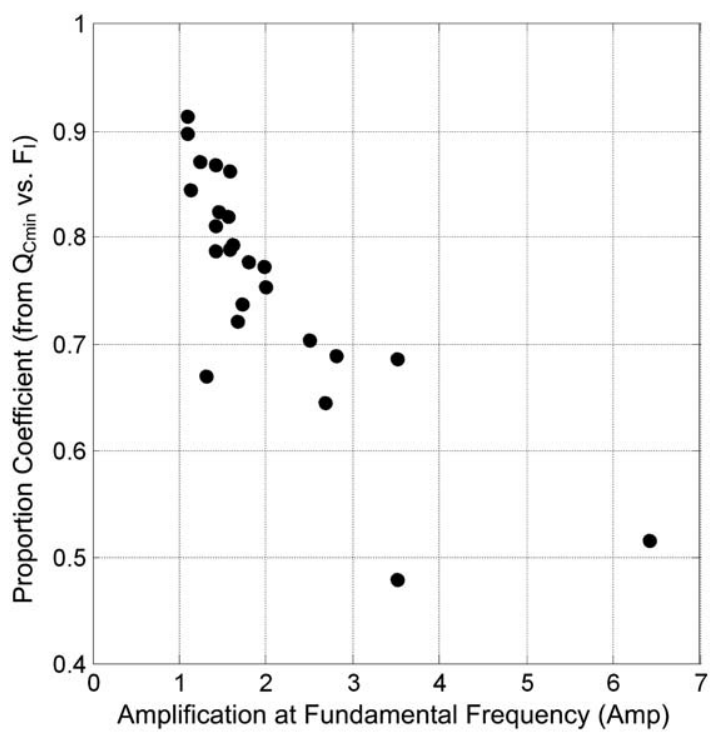

Figure 16. Proportionality coefficient of $Q_{C \min }$ versus $F I$ plotted against the amplification at the fundamental frequency of the soil profile for constant ductility ratio inelastic SDOF oscillators $(\mu=4)$ (compare to Figure 13 for $R_{y}=4$ ).

\section{CONCLUSIONS}

We investigated the variability in nonlinear structural response predictions that results from the site response models implemented in synthetic ground motion simulations. We studied typical profiles in Southern California, and first illustrated that the variability in site response predictions resulting from the use of different soil models may be mapped in an intensity-frequency $\left(P G A_{R O}-F I\right)$ domain. We presented next quantitative relations between the deviation of empirical site response models from nonlinear analyses and these site-motion parameters.

Next, we illustrated that the site response modeling variability yielded consistent bias and uncertainty in the prediction of inelastic SDOF response. Results indicated that, with the exception of very stiff profiles, the predicted inelastic deformation ratios at the majority of sites computed using visco-elastic site response models are consistently lower than the ones evaluated using incremental nonlinear models around a particular period range. Results also showed that the former are less variable than the latter. These observations imply that design procedures of inelastic structures that involve synthetic ground motions without proper consideration of nonlinear site effects, may be yield underestimated mean and uncertainty of deformation demand.

It was found that the mean bias in the inelastic deformation ratio $(C)$ prediction correlated well with characteristics of input ground motions and site parameters. In general, the bias in $C$ predictions was shown to increase with increasing ground motion intensity (PGA), 
decreasing $V_{S 30}$, and increasing first mode site amplification. Overall, the bias is reduced as more elaborate site response models are implemented.

This ground motion $\left(P G A_{R O}\right.$ and $\left.F_{I}\right)$ and site ( $V_{S 30}$ and first mode amplification) dependency of the mean bias in $\mathrm{C}$ predictions implies that the source of bias is most likely the inability of simplified models (linear viscoelastic, empirical amplification factors) to capture nonlinear site effects and the corresponding altering of ground motion frequency content. This conjecture is also favorable to the establishment of a guideline for efficient integration of nonlinear site response models into end-to-end ground motion simulations.

\section{ACKNOWLEDGMENTS}

This research was supported by the Southern California Earthquake Center. SCEC is funded by NSF Cooperative Agreement EAR-0529922 and USGS Cooperative Agreement 07HQAG0008. The SCEC contribution number for this paper is 1259.

\section{REFERENCES}

Assimaki, D., Li, W., Steidl, J., and Schmedes, J., 2008. Quantifying nonlinearity susceptibility via site response modeling uncertainty at three sites in the Los Angeles basin, Bulletin of the Seismological Society of America 98, 2364-2390.

Bardet, J. P., and Tobita, T., 2001. NERA: A Computer Program for Nonlinear Earthquake Site Response Analyses of Layered Soil Deposits, Technical Report, University of Southern California, Los Angeles, CA.

Bardet, J. P., Ichii, K., and Lin, C. H., 2000. EERA: A Computer Program for Equivalent-Linear Earthquake Site Response Analyses of Layered Soil Deposits, Technical Report, University of Southern California, Los Angeles, CA.

Bazzurro, P., Sjoberg, B., and Luco, N., 2004. Post-Elastic Response of Structures to Synthetic Ground Motions, Technical Report, AIR Worldwide Corporation.

Berrill, J., 1977. Site effects during the San Fernando, California, earthquake, in Proceedings of the Sixth World Conf. on Earthquake Engineering, India, 432-438.

Bommer, J., Scott, S., and Sarma, S., 2000. Hazard-consistent earthquake scenarios, Soil Dynamics and Earthquake Engineering 19, 219-231.

Boore, D. M., 1983. Stochastic simulation of high-frequency ground motions based on seismological models of the radiated spectra, Bull. Seism. Soc. Am. 73, 1865-1894.

Boore, D. M., and Atkinson, G. M., 2008. Ground-motion prediction equations for the average horizontal component of PGA, PGV, and 5\%-damped PSA at spectral periods between $0.01 \mathrm{~s}$ and 10.0 s, Earthquake Spectra 24, 99-138.

Borcherdt, R. D., and Gibbs, J. F., 1976. Effects of local geological conditions in the San Francisco bay region on ground motions and the intensities of the 1906 earthquake, Bulletin of the Seismological Society of America 66, 467-500.

Building Seismic Safety Council (BSSC), 2003. NEHRP Recommended Provisions for Seismic Regulations for New Buildings and Other Structures (FEMA 450), Technical Report, prepared by the Building Seismic Safety Council for the Federal Emergency Management Agency, Washington, D.C.

Chin, B.-H., and Aki, K., 1991. Simultaneous study of the source, path, and site effects on strong ground motion during the 1989 Loma Prieta earthquake: A preliminary result on pervasive nonlinear site effects, Bulletin of the Seismological Society of America 81, 1859-1884. 
Chopra, A. K., and Chintanapakdee, C., 2004. Inelastic deformation ratios for design and evaluation of structures: Single-degree-of-freedom bilinear systems, Journal of Structural Engineering 130, 1309-1319.

Darragh, R. B., and Shakal, A. F., 1991. The site response of two rock and soil station pairs to strong and weak ground motion, Bulletin of the Seismological Society of America 81, 18851899.

Duke, C., and Mal, A., 1978. Site and Source Effects on Earthquake Ground Motion, Technical Report, University of California, Los Angeles.

Ellis, G. W., and Cakmak, A. S., 1987. Modeling Earthquake Ground Motions in Seismically Active Regions Using Parametric Time Series Methods, Technical Report, NCEER-87-0014, National Center for Earthquake Engineering Research.

Graves, R. W., and Pitarka, A., 2010. Broadband ground motion simulation using a hybrid approach, Bulletin of the Seismological Society of America 100, 2095-2123.

Hartzell, S., 1992. Site response estimation from earthquake data, Bulletin of the Seismological Society of America 82, 2308-2327.

Idriss, I. M., and Seed, H., 1968. Seismic response of horizontal soil layers, J. Soil Mech. and Found. Div., ASCE, 94, 1003-1031.

Iwan, W. D., 1967. On a class of models for the yielding behavior of continuous and composite systems, Journal of Applied Mechanics 34, 612-617.

Joyner, W. B., Warrick, R. E., and Oliver, III, A. A., 1976. Analysis of seismograms from a downhole array in sediments near San Francisco Bay, Bulletin of the Seismological Society of America 66, 937-958.

Kanai, K., 1961. An empirical formula for the spectrum of strong earthquake motions, Bull. Earthquake Res. Inst. 39, 85-95.

Katsanos, E. I., Sextos, A. G., and Manolis, G. D., 2010. Selection of earthquake ground motion records: A state-of-the-art review from a structural engineering perspective, Soil Dynamics and Earthquake Engineering 30, 157-169.

Kausel, E., and Assimaki, D., 2002. Seismic simulation of inelastic soils via frequency-dependent moduli and damping, Journal of Engineering Mechanics 128, 34-47.

Kramer, S. L., 1996. Geotechnical Earthquake Engineering, Prentice-Hall, Upper Saddle River, NJ, 653 pp.

Li, W., Assimaki, D., and Fragiadakis, M., 2009. Nonlinear site response modeling variability in "rupture-to-rafters" ground motion simulations, in Proc. 2nd International Conference on Computational Methods in Structural Dynamics and Earthquake Engineering (COMPDYN 2009), Rhodes, Greece.

Li, W., and Assimaki, D., 2010. Site and ground motion dependent parametric uncertainty of nonlinear site response analyses in earthquake simulations, Bulletin of the Seismological Society of America 100, 995-1009.

Matasovic, N., and Vucetic, M., 1993. Cyclic characterization of liquefiable sands, Journal of Geotechnical Engineering 119, 1805-1822.

Miranda, E., 1993. Site-dependent strength-reduction factors, Journal of Structure Engineering 119, 3503-3519.

Miranda, E., 2000. Inelastic displacement ratios for structures on firm sites, Journal of Structural Engineering 126, 1150-1159. 
Miranda, E., 2001. Estimation of inelastic deformation demands of SDOF systems, Journal of Structural Engineering 127, 1005-1012.

Naeim, F., and Lew, M., 1995. On the use of design spectrum compatible time histories, Earthquake Spectra 11, 111-127.

O'Connor, I. M., and Ellingwood, B. R., 1992. Site-dependent models of earthquake ground motion, Earthquake Engineering and Structural Dynamics 21, 573-589.

Paparizos, G., 1986. Some Observations on the Random Response of Hysterestic Systems, Technical Report, Report No. EERL86-02, California Institute of Technology, Pasadena, CA.

Reiter, L., 1990. Earthquake Hazard Analysis: Issues and Insights, Columbia University Press, New York, $254 \mathrm{pp}$.

Ruiz-Garcia, J., and Miranda, E., 2004. Inelastic displacement ratios for design of structures on soft soils sites, Journal of Structural Engineering 130, 2051-2061.

Safak, E., 1997. Models and methods to characterize site amplification from a pair of records, Earthquake Spectra 13, 97-129.

Schnabel, P. B., Lysmer, J., and Seed, H. B., 1972. Shake: A Computer Program for Earthquake Response Analysis of Horizontally Layered Sites, Technical Report, Earthquake Engineering Research Center, University of California, Berkeley.

Silva, W. J., and Stark, C. L., 1992. Source, Path, and Site Ground Motion Model for the 1989 M 6.9 Loma Prieta Earthquake, Technical Report, Calif. Div. Mines Geol. Final Rept.

Su, F., Aki, K., Teng, T., Koyanagi, S., and Mayeda, M., 1992. The relation between siteamplification factor and surficial geology in central California, Bulletin of the Seismological Society of America 82, 580-602.

Tajimi, K., 1960. A statistical method of determining the maximum response of a building structure during an earthquake, in Proc. 2nd World Conf. Earthquake Eng., Tokyo and Kyoto, Japan.

Veletsos, N., Newmark, N. M., and Chepalati, C., 1965. Deformation spectra for elastic and elastoplastic systems subjected to ground shock and earthquake motion, in Proc. $3^{\text {rd }}$ World Conf. on Earthquake Engineering, Vol. II, Wellington, New Zealand, 663-682.

Whitman, R. V., and Protonotarios, J. N., 1977. Inelastic response to site-modified ground motions, Journal of the Geotechnical Engineering Division 103, 1037-1053.

Wiggins, J., 1964. Effects of site conditions on earthquake intensity, J. Structural Div., ASCE, 90, 279-313.

(Received 31 January 2010; accepted 1 September 2011) 